\title{
Erratum to: Optimal selection of annulus radius ratio to enhance heat transfer with minimum entropy generation in developing laminar forced convection of water- $\mathrm{Al}_{2} \mathrm{O}_{3}$ nanofluid flow
}

\author{
Siavashi Majid, Jamali Mohammad \\ Applied Multi-Phase Fluid Dynamics Lab., School of Mechanical Engineering, \\ Iran University of Science and Technology, Tehran, Iran \\ (C) Central South University Press and Springer-Verlag GmbH Germany 2017
}

Erratum to: J. Cent. South Univ. (2017) 24: 1850-1865

DOI: https://doi.org/10.1007/s11771-017-3593-7

Authors' first and last names were interchanged in the original version of the article and they should be replaced as follows: Majid Siavashi, Mohammad Jamali.

Corresponding author: Majid Siavashi, Assistant Professor, PhD; Tel: +98-21-77240391; E-mail: maiavashi@iust.ac.ir 